\title{
Groundwater Quality in the Antelope Valley, California
}

Groundwater provides more than $\mathbf{4 0}$ percent of California's drinking water. To protect this vital resource, the State of California created the Groundwater Ambient Monitoring and Assessment (GAMA) Program. The Priority Basin Project of the GAMA Program provides a comprehensive assessment of the State's groundwater quality and increases public access to groundwater-quality information. Antelope Valley is one of the study areas being evaluated.

\section{The Antelope Study Area}

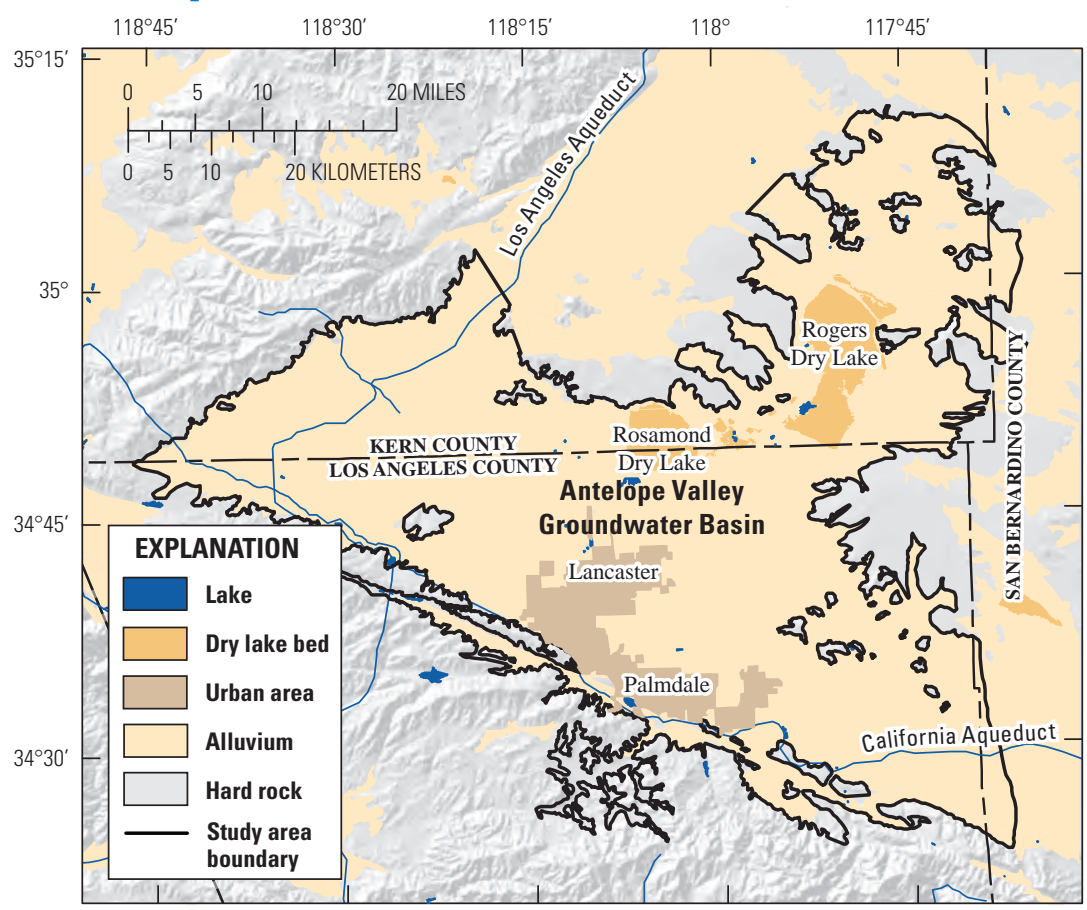

The Antelope study area is approximately 1,600 square miles (4,144 square kilometers) and includes the Antelope Valley groundwater basin (California Department of Water Resources, 2003). Antelope Valley has an arid climate and is part of the Mojave Desert. Average annual rainfall is about 6 inches (15 centimeters). The study area has internal drainage, with runoff from the surrounding mountains draining towards dry lakebeds in the lower parts of the valley. Land use in the study area is approximately 68 percent (\%) natural (mostly shrubland and grassland), 24\% agricultural, and 8\% urban. The primary crops are pasture and hay. The largest urban areas are the cities of Palmdale and Lancaster (2010 populations of 152,000 and 156,000, respectively).

Groundwater in this basin is used for public and domestic water supply and for irrigation. The main water-bearing units are gravel, sand, silt, and clay derived from surrounding mountains. The primary aquifers in Antelope Valley are defined as those parts of the aquifers corresponding to the perforated intervals of wells listed in the California Department of Public Health database. Public-supply wells in Antelope Valley are completed to depths between 360 and 700 feet (110 to 213 meters), consist of solid casing from the land surface to a depth of 180 to 350 feet (55 to 107 meters), and are screened or perforated below the solid casing. Recharge to the groundwater system is primarily runoff from the surrounding mountains, and by direct infiltration of irrigation and sewer and septic systems. The primary sources of discharge are pumping wells and evapotranspiration near the dry lakebeds.

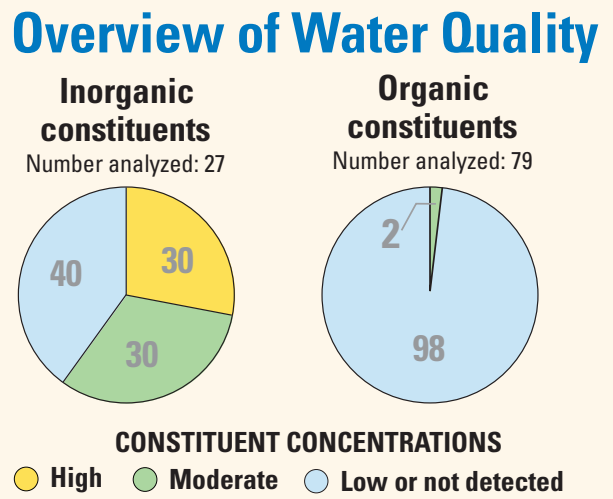

Pie charts illustrate the proportion of the primary aquifers, on an areal basis, with concentrations in the three specified categories.

GAMA’s Priority Basin Project evaluates the quality of untreated groundwater. However, for context, benchmarks established for drinkingwater quality are used for comparison. Benchmarks and definitions of high, moderate, and low concentrations are discussed in the inset box on page 3 . The USGS sampled 56 wells for this assessment; data from the California Department of Public Health database were used to supplement USGS data.

Many inorganic constituents occur naturally in groundwater. The concentrations of the inorganic constituents can be affected by natural processes as well as by human activities. In the Antelope Valley study area, one or more inorganic constituents were present at high concentrations in $30 \%$ of the primary aquifers and at moderate concentrations in $30 \%$.

Organic constituents are found in products used in the home, business, industry, and agriculture. Organic constituents can enter the groundwater system through normal usage, spills, or improper disposal. In the Antelope Valley study area, organic constituents were present at moderate concentrations in $2 \%$ of the primary aquifers. 


\section{RESULTS: Groundwater Quality in the Antelope Study Area}

\section{INORGANIC CONSTITUENTS}

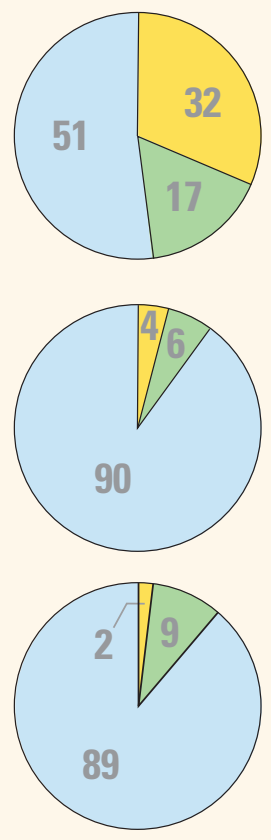

Trace elements

\section{Radioactive constituents}

\section{Nutrients}

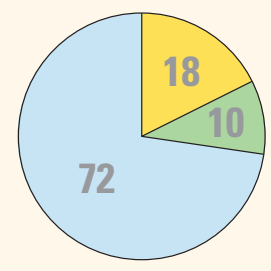

\section{Other inorganic constituents}

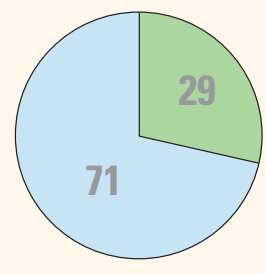

\section{Perchlorate}

\section{Inorganic Constituents with Human-Health Benchmarks}

Trace elements are naturally present in the minerals in rocks and soils, and in the water that comes into contact with those materials; their concentrations can be affected by human activities. In the Antelope study area, trace elements were present at high concentrations in 32\% of the primary aquifers, on an areal basis, and at moderate concentrations in $17 \%$. Of the 17 trace elements with human-health benchmarks analyzed in this study, 5 were detected at high concentrations: aluminum, arsenic, vanadium, boron, and fluoride. Chromium, lead, and molybdenum were present at moderate concentrations.

Radioactivity is the release of energy or energetic particles during structural changes in the nucleus of an atom. Most of the radioactivity in groundwater comes from decay of naturally occurring isotopes of uranium and thorium that are present in minerals in the aquifer. In the Antelope study area, radioactive constituents were detected at concentrations above benchmarks in $4 \%$ of the primary aquifers, and at moderate values in $6 \%$. Six radioactive constituents were analyzed; of these, gross alpha radioactivity was detected above human-health benchmarks. Uranium was present at moderate concentrations.

Nutrients, such as nitrate and nitrite, are naturally present at low concentrations in groundwater. High and moderate concentrations generally occur as a result of human activities, such as fertilizer application, livestock waste, or septic-system seepage. Of the three nutrients with health-based benchmarks analyzed, one, nitrate, was detected at concentrations above benchmarks.

\section{Inorganic Constituents with Non-Health Benchmarks}

(Not included in water-quality overview charts shown on the front page)

Other inorganic constituents, such as total dissolved solids and iron, affect the aesthetic properties of water, such as taste, color, or odor. In the Antelope study area, these constituents were present at high concentrations in $18 \%$ of the primary aquifers, and at moderate concentrations in $10 \%$. Of the seven constituents with non-healthbased benchmarks that were analyzed, three (iron, manganese, and total dissolved solids) were detected above benchmarks. Sulfate and chloride were detected at modertate concentrations.

\section{Special Interest: Perchlorate}

Perchlorate is an inorganic constituent which has been regulated in California drinking water since 2007. It is an ingredient in rocket fuel, fireworks, safety flares,

may be present in some fertilizers, and also occurs naturally at low concentrations in groundwater. In the Antelope study area, perchlorate was found at moderate concentrations in $29 \%$ of the primary aquifers. 


\section{ORGANIC CONSTITUENTS}
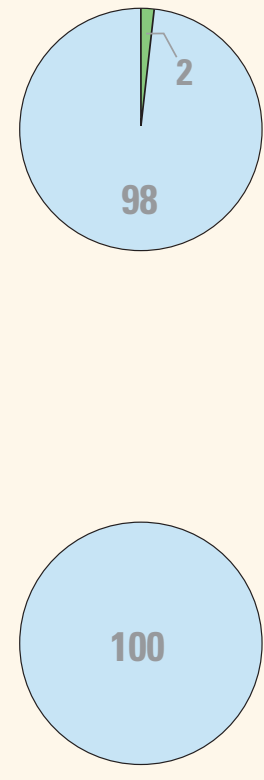
Pesticides

\section{Volatile organic compounds}

\section{Organic Constituents with Human-Health Benchmarks}

The Priority Basin Project uses laboratory methods that can detect the presence of volatile organic compounds (VOCs) and pesticides at very low concentrations, far below human-health benchmarks. VOCs and pesticides detected at these low concentrations can be used to help trace water from the land surface into the aquifer system.

\section{Volatile Organic Compounds}

VOCs are present in many household, commercial, industrial, and agricultural products, and can form during the disinfection of water supplies; they are characterized by their tendency to volatilize into the air. Of 56 VOCs with health-based benchmarks analyzed in the Antelope Valley study area, only the VOC trichloromethane (chloroform) was detected at moderate concentrations in $2 \%$ of the primary aquifers. No VOCs were detected at high concentrations in the primary aquifers.

\section{Pesticides}

Pesticides are used on lawns, in gardens, around buildings, along roads, and in agriculture to help control unwanted vegetation (weeds), insects, fungi, and other pests. In the Antelope Valley study area, pesticides were not detected or were only detected at low concentrations. Of the 20 pesticides with health-based benchmarks that were analyzed, none were detected at high or moderate concentrations in the primary aquifers.

\section{BENCHMARKS FOR EVALUATING GROUNDWATER OUALITY}

GAMA's Priority Basin Project uses benchmarks established for drinking water to provide context for evaluating the quality of untreated groundwater. After withdrawal, groundwater may be disinfected, filtered, mixed, or exposed to the atmosphere before being delivered to consumers. Federal and California regulatory benchmarks for protecting human health (Maximum Contaminant Level, MCL) are used when available. Otherwise, nonregulatory benchmarks for protecting human health (Notification Level, NL, and Lifetime Health Advisory, HAL) and nonregulatory benchmarks for protecting aesthetic properties such as taste and odor (Secondary Maximum Contaminant Level, SMCL) are used.

CONSTITUENT CONCENTRATIONS

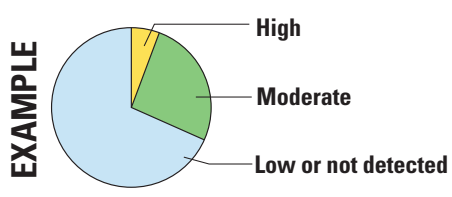

Values are a percentage of the area of the primary aquifers with concentrations in the three specified categories.

\section{High, moderate, and low concentrations are defined relative to benchmarks}

Concentrations are considered high if they are greater than a benchmark. For inorganic constituents, concentrations are moderate if they are greater than one-half of a benchmark. For organic and special-interest constituents, concentrations are considered moderate if they are greater than one-tenth of a benchmark; this lower threshold was used because organic constituents are generally less prevalent and have smaller concentrations relative to benchmarks than inorganic constituents. Low concentrations include nondetections and values less than moderate concentrations. Methods for evaluating water quality are discussed by Milby Dawson and Belitz (2012). 


\section{Trace Element Concentrations Throughout the California Desert Region}

Trace elements were present at high concentrations in all of the Desert primary aquifers. In Antelope, they were high in 32\% of the primary aquifers, on an areal basis; the range of high trace element percentages in the Desert Region study areas was 15 to 54\% (Milby Dawson and Belitz, 2012). The highest percentages in Antelope valley were arsenic (high in $28 \%$ of the primary aquifers), vanadium (6\%), and boron (3\%). Arsenic and boron were detected at high concentrations in all of the Desert primary aquifers; vanadium was detected at high concentrations in three of the six Desert Region study areas. Arsenic was high in a larger portion of the Antelope Valley primary aquifers than in any of the other Desert Region study areas.

\section{Desert Region Study Areas}

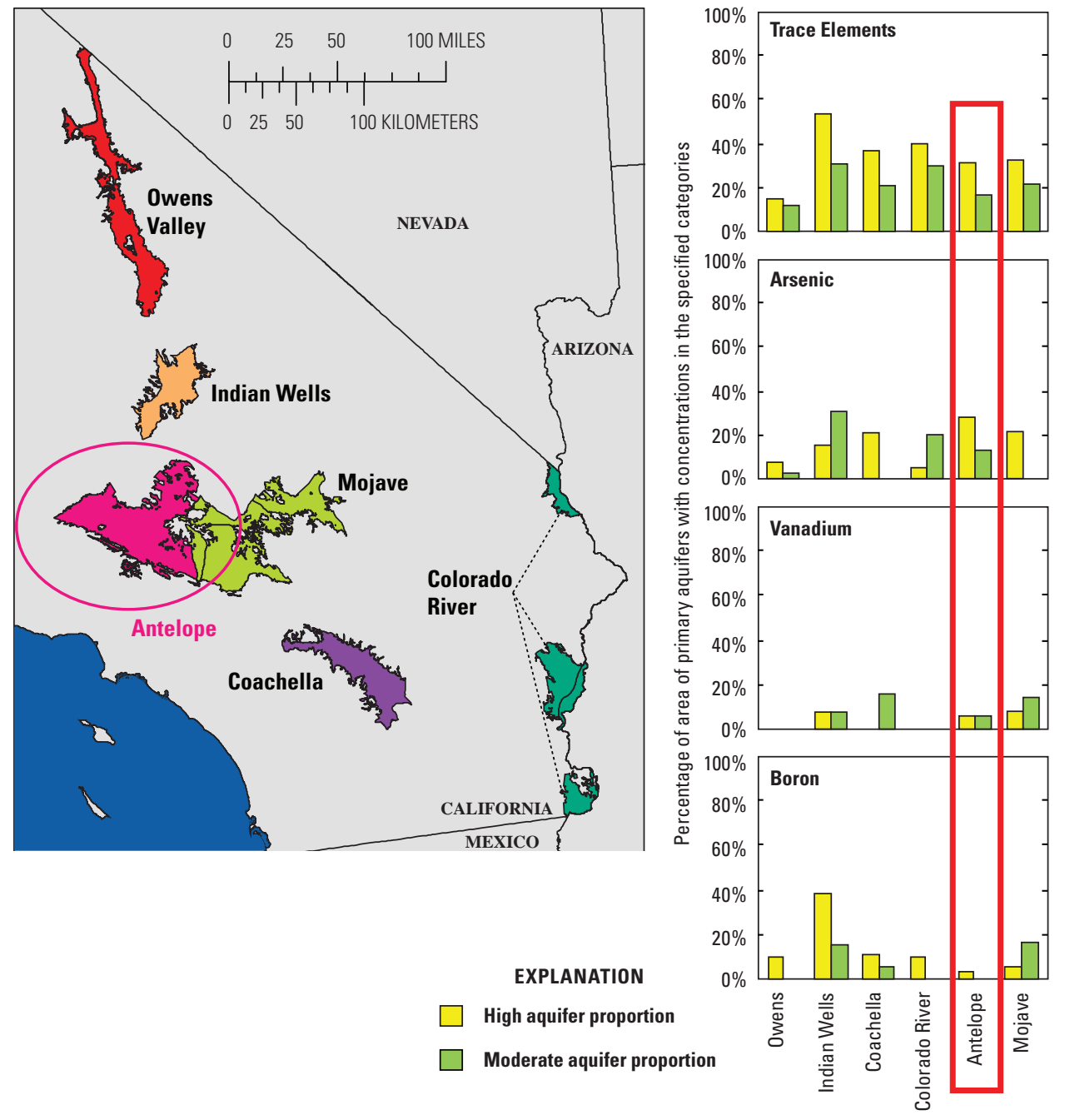

By Barbara J. Milby Dawson and Kenneth Belitz

\section{SELECTED REFERENCES}

California Department of Water Resources, 2003, California’s groundwater: California Department of Water Resources Bulletin 118, 246 p., available at http://www.water.ca.gov/groundwater/bulletin118/update2003.cfm/

Milby Dawson, B.J., and, Belitz, K., 2010, Status of groundwater quality in the California Desert Region, 2006-2008-California GAMA Program Priority Basin Project: U.S. Geological Survey Scientific Investigations Report 2012-5040, 100 p.

Schmitt, S.J., Milby Dawson, B.J., and Belitz, K., 2009, Groundwater quality data in the Antelope Valley Study Unit, 2008-Results from the California GAMA Program: U.S. Geological Survey Data Series 479, 79 p., available at http://pubs.usgs.gov/ds/479/

\section{Priority Basin Assessments}

GAMA's Priority Basin Project (PBP) assesses water quality in that part of the aquifer system used for drinking water, primarily public supply. Water quality in shallower and deeper parts may differ from water quality in the primary aquifers. GAMA's Domestic Well Project assesses water quality in the shallower parts of the aquifer system. Ongoing assessments are being conducted in more than 120 basins throughout California.

The PBP assessments are based on a comparison of constituent concentrations in untreated groundwater with benchmarks established for the protection of human health and for aesthetic concerns. The PBP does not evaluate the quality of drinking water delivered to consumers.

The PBP uses two approaches for assessing groundwater quality. The first approach uses a network of wells to provide a statistically based assessment of the status of groundwater quality. The second approach uses additional wells to help assess the factors that affect water quality. Both approaches use data routinely collected for regulatory compliance, as well as data collected by the PBP. The PBP includes chemical analyses not generally available as part of regulatory compliance monitoring, including measurements at concentrations much lower than human-health benchmarks, and measurement of constituents that can be used to trace the sources and movement of groundwater.

\section{For more information}

Technical reports and hydrologic data collected for the GAMA Program may be obtained from:

GAMA Program Unit

U.S. Geological Survey California Water Science Center 4165 Spruance Road, Suite 200

San Diego, CA 92101

Telephone number: (619) 225-6100

WEB: http://ca.water.usgs.gov/gama

GAMA Program Unit

State Water Resources Control Board Division of Water Quality

PO Box 2231, Sacramento, CA 95812

Telephone number: (916) 341-5779

WEB: http://www.waterboards.ca.gov/gama/ 